\title{
Retraction Note to: Slope ecological restoration based on image classification and construction of sports fitness index
}

\author{
Huang $\mathrm{He}^{1}$
}

Published online: 3 November 2021

(c) Saudi Society for Geosciences 2021

Retraction Note to: Arabian Journal of Geosciences (2021) 14: 1650 https://doi.org/10.1007/s12517-021-08069-0

The Editor-in-Chief and the Publisher have retracted this article because the content of this article is nonsensical. The peer review process was not carried out in accordance with the Publisher's peer review policy. The author has not responded to correspondence regarding this retraction.

The original article can be found online at https://doi.org/10.1007/ s12517-021-08069-0.

Huang He

huanghe4142486@163.com

1 Guangxi College of Sports and Physical Education, Nanning 530012, Guangxi, China 